\title{
Detection of a High-Density Brachiolaria-Stage Larval Population of Crown-of-Thorns Sea Star (Acanthaster planci) in Sekisei Lagoon (Okinawa, Japan)
}

\author{
Go Suzuki ${ }^{1,+}$, Nina Yasuda ${ }^{2, *,+}$, Kohta Ikehara ${ }^{3,4}$, Kouki Fukuoka ${ }^{1}$, Takahiko Kameda ${ }^{1}$, \\ Sayaka Kai ${ }^{1}$, Satoshi Nagai ${ }^{5}$, Atushi Watanabe ${ }^{6}$, Takashi Nakamura ${ }^{6}$, Shunsuke Kitazawa ${ }^{7}$, \\ Lawrence Patrick C. Bernardo $^{8}$, Tatsuya Natori ${ }^{3}$, Momoka Kojima ${ }^{3}$ and Kazuo Nadaoka ${ }^{6}$ \\ 1 Research Center for Subtropical Fisheries, Seikai National Fisheries Research Institute, Ishigaki 9070451, \\ Japan; gosuzu@fra.affrc.go.jp (G.S.); fukuokak@fra.affrc.go.jp (K.F.); takukame@affrc.go.jp (T.K.); \\ goroumaru48@hotmail.com (S.K.) \\ 2 Organization for Promotion of Tenure Track, Miyazaki University, Miyazaki 8892192, Japan \\ 3 Department of Marine Biology and Environmental Sciences, Faculty of Agriculture, Miyazaki University, \\ Miyazaki 8892192, Japan; kotaikehara@gmail.com (K.I.); tatsuya.n.22128@gmail.com (T.N.); \\ gd13010@student.miyazaki-u.ac.jp (M.K.) \\ 4 Idea Consultants, Inc., Okinawa 900-0003, Japan \\ 5 Research Center for Aquatic Genomics, National Research Institute of Fisheries Science, Kanazawa-ku \\ 236-8648, Japan; snagai@affrc.go.jp \\ 6 School of Environment and Society, Department of Transdisciplinary Science and Engineering, Tokyo \\ Institute of Technology, Meguro-ku 1528550, Japan; watanabe.a.ah@m.titech.ac.jp (A.W.); \\ nakamura.t.av@m.titech.ac.jp (T.N.); nadaoka.k.aa@m.titech.ac.jp (K.N.) \\ 7 Graduate School of Information Science and Engineering, Department of Mechanical and Environmental \\ Informatics, Tokyo Institute of Technology, Meguro-ku 1528550, Japan; kitazawa.s.aa@m.titech.ac.jp \\ 8 Graduate School of Science and Engineering, Department of Civil Engineering, Tokyo Institute of \\ Technology, Meguro-ku 1528550, Japan; loric.bernardo@gmail.com \\ * Correspondence: Nina27@cc.miyazaki-u.ac.jp; Tel./Fax: +81-985-58-7233 \\ + These authors contributed equally to this work.
}

Academic Editor: Zoe Richards

Received: 24 January 2016; Accepted: 28 March 2016; Published: 31 March 2016

\begin{abstract}
Outbreaks of the crown-of-thorns sea star (Acanthaster planci) are likely to be strongly associated with drastic changes in larval survival influenced by food availability. However, no quantitative or qualitative data are available on the distribution of $A$. planci larvae in the field nor on the environmental factors that influence their survivorship. Here we use a DNA barcoding approach to describe the distribution of A. planci larvae in Sekisei Lagoon, Ryukyu Archipelago, Japan after conducting three days of high-intensity sampling. High densities (53.3 individuals $/ \mathrm{m}^{3}$ ) of A. planci larvae were found outside of Yonara Channel, which is the largest reef channel in this lagoon. Surprisingly, most (94\%) of the aggregated larvae were advanced-stage brachiolaria. Considering that it takes several days to develop to this stage, this result demonstrates that $A$. planci larvae were floating for some time and maintaining a high-density population. However, this dense larval cloud disappeared immediately after a typhoon. No spatial correlation was found between larval density and either nutrient or chlorophyll $a$ concentrations, suggesting that $A$. planci larvae do not necessarily aggregate in nutrient-rich water. These data suggest that some high-density populations of late developmental stage $A$. planci larvae were produced under a low phytoplankton concentration and could potentially trigger an adult outbreak. Consequently, our data suggest that adult outbreaks may not necessarily be triggered by food availability alone.
\end{abstract}

Keywords: larval dispersal; plankton towing; DNA barcoding; mitochondrial DNA; sea star; population outbreak 


\section{Introduction}

Outbreaks of the crown-of-thorns sea star (COTS; Acanthaster planci), which feeds voraciously on corals, have threatened Indo-Pacific coral reefs for the last few decades [1]. Predation by A. planci accounted for $42 \%$ of the estimated $50 \%$ decline in initial coral cover on the Great Barrier Reef (Australia) between 1985 and 2002 [1]. Previous A. planci outbreaks occurred in the 1960s-70s and 1990s in the same region [2-4] and intermittently in the Ryukyu Archipelago, Japan since the 1940s [5-7]. Because A. planci has high fecundity, the major cause of these outbreaks may be attributed to drastic annual fluctuations in survival of $A$. planci larvae [8], although other natural or anthropogenic causes may also be associated with a population outbreak across Indo-Pacific Oceans such as in the Philippines, Red Sea, and Hawaii, reviewed in Pratchett et al. (2014) and Brikeland and Lucas (1990) [1,9].

The A. planci pelagic larval stage is $2-6$ weeks in duration [9-11], during which the larvae feed on phytoplankton $[12,13]$. The major cause for the dramatic fluctuations in larval survival is thought to be nutrients from terrestrial runoff [12-14]. This inflow of nutrients increases during heavy rainfall years with flood events and triggers the increased phytoplankton that forms a major component of the A. planci larval diet. A feeding experiment revealed that $A$. planci larvae starve at chlorophyll $a(\mathrm{Chl}-a)$ concentrations $<0.25 \mu \mathrm{g} / \mathrm{L}$, whereas they are released from trophic level limitations at concentrations $>2 \mu \mathrm{g} / \mathrm{L}$ [8]. One study suggested that a $1 \mu \mathrm{g} / \mathrm{L}$ phytoplankton concentration is optimal for larval success [15]. Another study showed phenotypic plasticity of $A$. planci larvae depending on phytoplankton availability, which also supports the larval survival hypothesis [16]. Predation pressure on post-settlement stage larvae may also play a role in driving outbreaks $[9,17,18]$.

A key factor associated with large outbreaks is the A. planci larval dispersal dynamic, which is associated with food availability, and may determine their survival along with the length of time in the water column. Despite the importance of understanding these dynamics, very little is known about how $A$. planci larvae are spatially distributed. Studies that used a pump during the A. planci spawning season detected larvae at a few sites $[10,19]$. A large-scale $A$. planci larval survey conducted on the Great Barrier Reef detected possible A. planci larval DNA via polymerase chain reaction (PCR) analysis in many of the seawater samples collected from different locations during a population outbreak [20]. However, the basic larval ecology of wild $A$. planci populations remains mostly unknown.

The aim of this study was to understand basic $A$. planci larval ecology, including how A. planci larvae are distributed around a coral reef, whether $A$. planci larvae are found in nutrient-rich water, which may increase their survival, and whether a natural disturbance, such as a typhoon, affects larval population dynamics. In this study, large-scale intensive sampling of reef water before and after a typhoon, where an A. planci outbreak was underway, was conducted to better understand A. planci larval distribution patterns during an outbreak. Seawater samples were also collected, and nutrient and Chl- $a$ concentrations were measured at each sampling site to identify the environmental factors determining larval distribution.

Our study area was the Sekisei Lagoon $\left(300 \mathrm{~km}^{2}\right)$ in the central Yaeyama Islands, located in the south Ryukyu Archipelago, Okinawa, Japan. The lagoon is roughly bounded by the islands of Ishigaki and Iriomote (Figure 1). Flow varies highly in Sekisei Lagoon owing to complex geographical land and reef features [21,22]. Significant red soil inflow is observed into Sekisei Lagoon from the mouth of the Todoroki and Miyara Rivers in southeastern Ishigaki Island following heavy precipitation [23] and likely contains high nutrient loads. Red soil runoff results from the development of land projects started in the 1970s [23]. Iriomote Island is much less developed and has a smaller population than that of Ishigaki Island, where intensive agriculture is underway. We describe the A. planci larval distribution in an archipelagic region adjacent to an island with a human population of approximately 50,000 . 


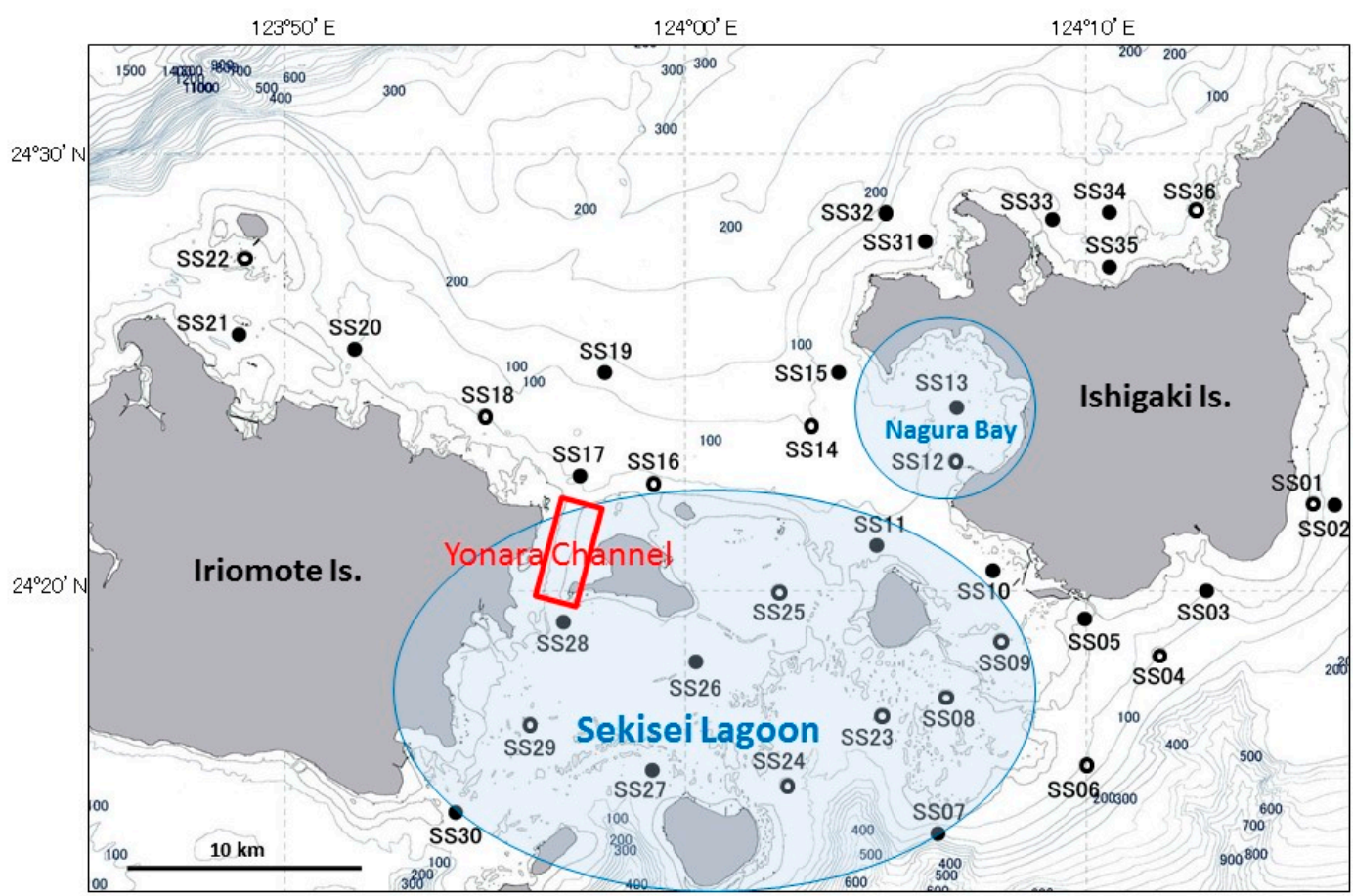

Figure 1. Map of the Yaeyama Islands study area. Black circles denote sites where both zooplankton and seawater samples were collected, and white circles denote sites where only seawater samples were collected.

\section{Materials and Methods}

\subsection{General Background Information and A. Planci Outbreak in the Yaeyama Islands}

A previous study on the A. planci spawning period on Ryukyu Island including Sekiseki Lagoon showed that peak spawning starts when water temperature exceeds $28^{\circ} \mathrm{C}$ [24]. According to data from a temperature logger deployed near Ishigaki Island (Nadaoka, unpublished data), peak spawning in the Yaeyama region presumably started in early June 2013 when water temperature exceeded $28^{\circ} \mathrm{C}$ just after the rainy season. The peak of the outbreak ( $>10$ individuals counted within 15 min of diving) was observed from 2006 to 2013; however, the main location of the outbreak changed continuously during this period. The highest $A$. planci density during this outbreak (118 individuals encountered per 15 min of diving) was recorded in 2011 in Yonara Channel [25]. Yonara Channel is one of the largest reef channels in this lagoon, with a 500-m width, 3-km length, and maximum depth of $30 \mathrm{~m}$. In 2013, 7000 and 2800 A. planci adults were removed from Nagura Bay and north Sekisei Lagoon, respectively. Although the number of $A$. planci adults decreased across the Yaeyama Islands in 2012 and 2013, control reports suggest that the outbreak continued longer in the northern Sekisei Lagoon reefs (Ministry of the Environment, unpublished data).

\subsection{A. Planci Larvae and Seawater Sampling}

Thirty sampling sites (SS1-30) were established around Sekisei Lagoon (Figure 1), and three field surveys using four boats were conducted on 17, 18, and 21 June 2013. The sea was calm for the first two survey days, but a small typhoon $(994 \mathrm{hPa}$ ) brought heavy rainfall (approximately $200 \mathrm{~mm}$ over 2 days) when it passed through the Yaeyama Islands on 19 June. Therefore, the locations of six sites were changed from the south to the north of Ishigaki Island (i.e., from SS1-4, 6, and 7 to SS31-36) for the final survey on 21 June to avoid the high waves on the south side of the island. These surveys were conducted during the day. Two surveys were conducted before the typhoon during the rising tide, and the last survey was conducted after the typhoon around the ebb tide. Seawater temperature, 
salinity, turbidity, and dissolved oxygen were measured from the surface to near bottom at all sites using four AAQ-RINKO water quality profilers (JFE-Advantech Co., Ltd., Tokyo, Japan). Seawater samples were collected at the surface using a bucket and $7 \mathrm{~m}$ below the surface using a NISKIN water sampler (General Oceanics Inc., Miami, FL, USA).

Zooplankton were collected at 16 of the 30 water sampling sites, including A. planci larvae, using a 45-cm diameter conical plankton net fitted with 60 or $63 \mu \mathrm{m}$ mesh (Norpac net [26]). The Norpac net was towed horizontally $7 \mathrm{~m}$ below the surface for $3 \mathrm{~min}$ at a speed of 1-2 knots. A flowmeter was calibrated during three replicate tows on an open frame (i.e., without a net). In a previous survey, more larvae were found at $7 \mathrm{~m}$ than at other depths, although there was a slight vertical distribution bias of A. planci larvae [19]. The volume of water filtered by the net was measured with a flowmeter (Rigo Co., Ltd., Tokyo, Japan) mounted at the net mouth. Zooplankton samples were kept alive in 1-L bottles in a cooler box on the boat and were transported to the laboratory, where they were filtered through a $60-\mu \mathrm{m}$ net and preserved in $100 \%$ ethanol. Seawater samples were preserved in $10-\mathrm{mL}$ containers for nutrient analyses and in 500-mL containers for Chl- $a$ analysis and kept on ice in a cooler box for laboratory analyses. No special permission was required to collect the water samples in Sekisei Lagoon because no endangered or protected species, such as corals, fish, or other macrobenthos, were included in our samples.

\subsection{Identification of A. Planci Larvae}

All zooplankton samples were divided into two 500-mL subsamples. Presumed sea star larvae were sorted from half of the zooplankton sample under a microscope, and each larva was placed in a different $1.5 \mathrm{~mL}$ microtube containing $>95 \%$ ethanol. Larval stages were identified in each sample under a microscope. Genomic DNA was extracted from each larval sample using a DNA extraction kit (DNeasy Blood and Tissue Kit; Qiagen, Tokyo, Japan). Primers (COTS-Contl-revs and COTS-Contl-fwd), which have been widely used for A. planci phylogeographic analysis [27-30], were applied to amplifying target sequences via PCR. Because the isolated larvae were occasionally difficult to amplify owing to the small amount of DNA, which degrades gradually over time, additional shorter mitochondrial DNA fragments were amplified using the newly designed primers (2aooniF: ATTTGGGGCCTGAGCAGGAATG, 2aooniR: GCCTCTTTCTACTCCGGCTGATG to amplify the cytochrome oxidase subunit 1 region and APDloop460Fin2 Dloopin2-fwd: YYYTTCTTAHTTYTYCGCTCCGC, and Dlooopin2-rvs: GCCAGGTCAGTTTCTATCTACGA to amplify the control region) at an annealing temperature of $60{ }^{\circ} \mathrm{C}$. All PCR-amplified fragments were purified using ExoSap, and the sequences were determined directly using the PCR primers and an ABi 3730 sequencer (Applied Biosystems, Foster City, CA, USA), followed by a manual check using Bioedit ver7 [31] and a BLAST search.

The other half of the plankton sample was used as a crude, unsorted sample, which included other organisms and detritus, from which genomic DNA was extracted using the hot-shot DNA extraction method [32]. The detection level of $A$. planci larvae in these samples was estimated using the PCR primers (COTS-Contl-revs and COTS-Contl-fwd). These primers can discriminate $A$. planci from a few common coral reef sea stars, such as Protoreaster spp., Linckia spp., and Culcita spp. [19].

\subsection{Estimating Nutrient and Chl-a Concentrations}

Nitrate $\left(\mathrm{NO}_{3}{ }^{-}\right)$, nitrite $\left(\mathrm{NO}_{2}^{-}\right)$, ammonia $\left(\mathrm{NH}_{4}{ }^{+}\right)$, phosphate $\left(\mathrm{PO}_{4}{ }^{3-}\right)$, and silicate $\left(\mathrm{SiO}_{2}\right)$ concentrations were determined colorimetrically using an autoanalyzer (QuAAtro-SFA analyzer; SEAL Analytical Ltd., Burgess Hill, UK) for the surface and $7 \mathrm{~m}$ below the surface samples. Three replicates of each sample were used. The accuracy of the estimates for all nutrients, except $\mathrm{NH}_{4}{ }^{+}$, was verified using reference materials obtained from KANSO Technos Japan [33].

Half of the $500-\mathrm{mL}$ seawater samples collected for estimating the size-fractionated Chl- $a$ concentrations ( $<2$ and $>2 \mu \mathrm{m}$ ) were sieved through a $2-\mu \mathrm{m}$ membrane filter $(<2 \mu \mathrm{m}$ fraction), and the remaining $250-\mathrm{mL}$ subsamples were not sieved to calculate the value of the large fraction $(>2 \mu \mathrm{m})$. Both 
subsamples were filtered through a GF/F filter, immersed in N,N-dimethylformamide, and stored at $-20^{\circ} \mathrm{C}$ until analysis [34]. Chl- $a$ concentration was determined fluorometrically (Model-10AU; Turner Designs, Fresno, CA, USA) according to the method described by Holm-Hansen et al. [35].

\subsection{Statistical Analyses}

A spatial autocorrelation analysis was performed for the $A$. planci larval distribution using GeoDa 1.4.6 (L. Anselin, Tempe, AZ, USA) for each sampling day $(n=3)$. First, we defined the two sites that were geographically the shortest distance from the target site as neighboring sites and calculated Global Molan's I [36]. The result was simulated by 99,999 randomizations and tested to determine if the distribution was spatially autocorrelated in all areas (significance level, 0.05). The shortest distances between sites were calculated using ArcGIS 10.2 (Environmental Systems Research Institute, Inc., Redlands, CA, USA) avoiding land area. Next, local Molan's I [37] was calculated for each site with 99,999 randomizations. This indicator is classified into four patterns if a site was spatially autocorrelated (significance level, 0.05), as follows.

(1) High-High: + at target site, + at neighboring site (larval density was significantly higher at the target and neighboring sites)

(2) High-Low: + at target site, - at neighboring site (larval density was significantly higher at the target site than that at the neighboring site)

(3) Low-High: - at target site, + at neighboring site (larval density was significantly lower at the target site than that at the neighboring site)

(4) Low-Low: - at target site, - at neighboring site (larval density was significantly lower at the target and neighboring sites)

In addition, the chi-square test was conducted for larval distribution determined for each sampling day to test the null hypothesis of a random distribution of $A$. planci larvae.

A bivariate spatial correlation analysis was performed to evaluate the relationship between A. planci distribution and temperature, salinity, and Chl-a, $\mathrm{NO}_{3}{ }^{-}, \mathrm{NO}_{2}{ }^{-}, \mathrm{NH}_{4}{ }^{+}, \mathrm{PO}_{4}{ }^{3-}$, and $\mathrm{SiO}_{2}$ concentrations.

\section{Results}

\subsection{Larval Distribution}

A total of 225 presumed sea star larvae were sorted from 17 sites throughout the three days of surveying (Table S1). Forty-two A. planci larvae were detected at nine sites, for which samples were sorted based on identifying the genetic sequence from a Blast search including very short sequence fragments; of these, the highest density (53.3 individuals $/ \mathrm{m}^{3}$ ) was recorded during the first survey in water outside the Yonara Channel (17 June, SS17; Figures 2b and 3). A. planci larvae were detected at three sites during the first survey, and larval densities at the other two sites (SS15 and 20) were low (0.5 and 2.2 individuals $/ \mathrm{m}^{3}$, respectively), suggesting that the larvae were concentrated in the Yonara Channel $(p<0.01$, chi-square test). The distribution pattern observed during the second survey was similar; the highest density $\left(17.1\right.$ individuals $\left./ \mathrm{m}^{3}\right)$ was found in the Yonara Channel $(p<0.01$, chi-square test), and a second population (2.6 individuals $/ \mathrm{m}^{3}$ ) was detected in the eastern part of Sekisei Lagoon, inside Nagura Bay, suggesting a concentration of larvae in the northern part of Yonara Channel (SS13; Figure 2c). No dense clouds of larvae were found in the waters near the Yonara Channel after the typhoon $\left(p>0.05\right.$, chi-square test); however, a small number of larvae $\left(<1.0\right.$ individuals $\left./ \mathrm{m}^{3}\right)$ were found at five sites, mainly in the northern part of Sekisei Lagoon (Figure 2d). Significant local spatial autocorrelation was detected only at SS17 and its neighboring site, and the values were classified in the High-Low and Low-High categories, respectively $(p<0.05)$.

The larval specimens collected were primarily late-stage brachiolaria ( $73.8 \%$ of total). This was particularly true for the Yonara Channel samples (SS17), where $94.1 \%$ of the larval population was 
composed of brachiolaria. Small numbers of gastrula (14.3\%) and bipinnaria (11.9\%), which are initial and mid-developmental stages, respectively, were detected in all samples.
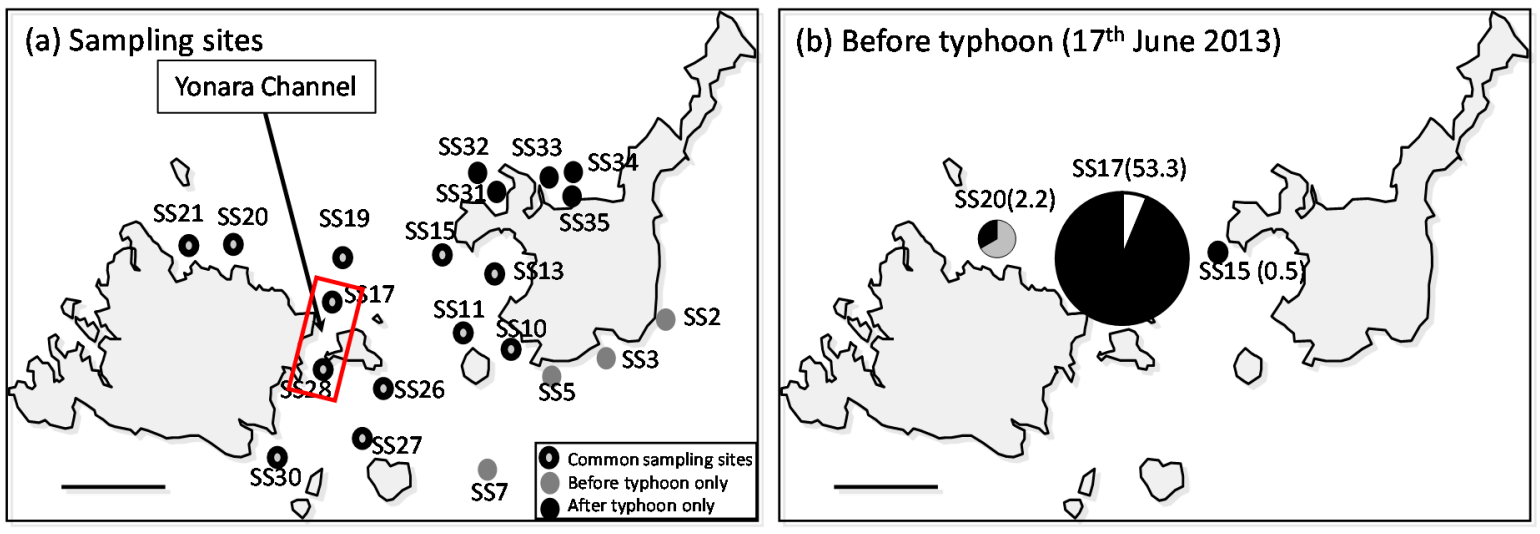

(c) Before typhoon (18 th $^{\text {th }}$ 2013)

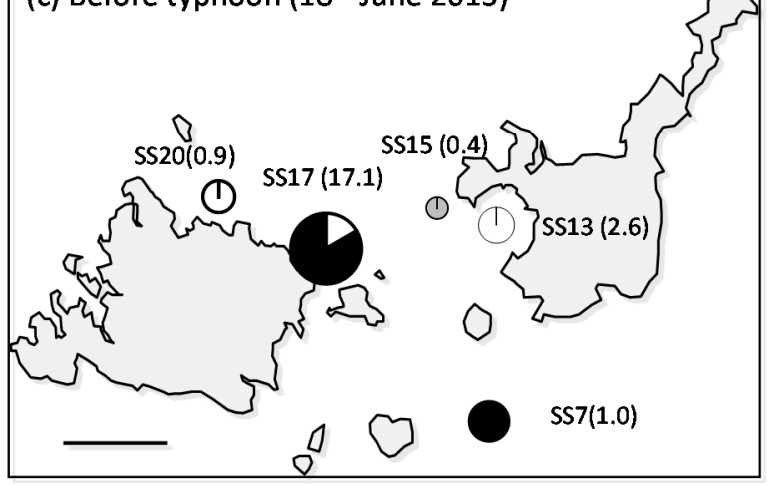

(d) After typhoon (21 ${ }^{\text {st }}$ June 2013)

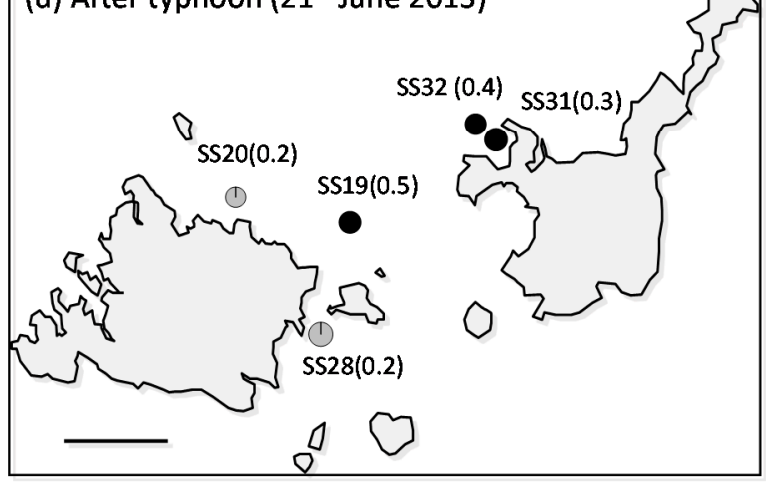

Figure 2. Distribution of Acanthaster planci larvae in the study area during the three field surveys. (a) Sampling sites; (b) distribution of identified A. planci larvae collected on 17 June 2013, (c) 18 June 2013, and (d) 21 June 2013 after a small typhoon. Numbers in parentheses indicate A. planci larval density (individuals $/ \mathrm{m}^{3}$ ). Colors in the pie chart represent larval developmental stages; black = brachiolaria, grey $=$ bipinnaria, and white $=$ gastrula.

The crude samples revealed the presence of $A$. planci DNA at three, three, and four sites from the three surveys, respectively (Table S1). However, no matches were found between sites where A. planci larvae were sorted by microscope and an A. planci-specific DNA sequence was detected by PCR (S1). Given the very low number of larvae detectable in a split sample $(500 \mathrm{~mL})$, it is reasonable to say that we could not detect $A$. planci larvae or DNA in either sample because only one of the samples actually contained a very small number of $A$. planci larvae. It is likely that the difference between the sorted and crude samples was either a result of false detection of $A$. planci DNA by PCR in the crude sample during screening and/or a false negative result caused by a failure to detect sea star larvae during the microscopic procedure.

Other larvae that were isolated and identified are, with the exception of A. planci, listed in Table S2. Other common coral reef sea stars, such as Linckia larvigata, Linckia guildingi, Mithrodia clavigera, and Culcita novaeguineae, were identified. We found at least seven Mithrodia sp. and one Culcita novaeguineae larva together with the A. planci larvae. However, no other larvae could be identified because of either the low similarity in the BLAST search or the degraded DNA. 

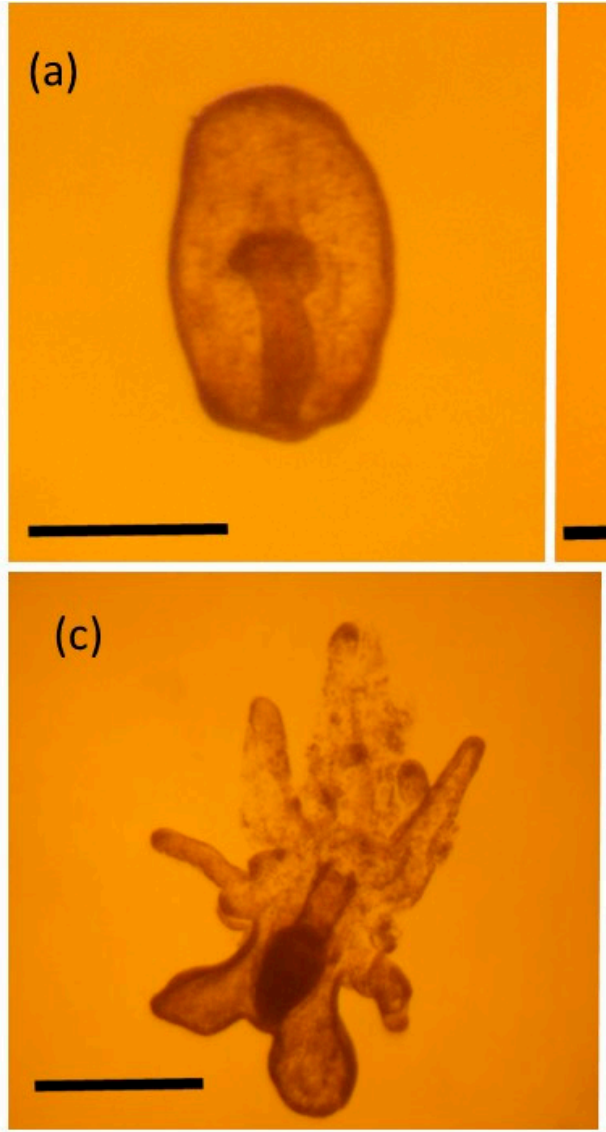
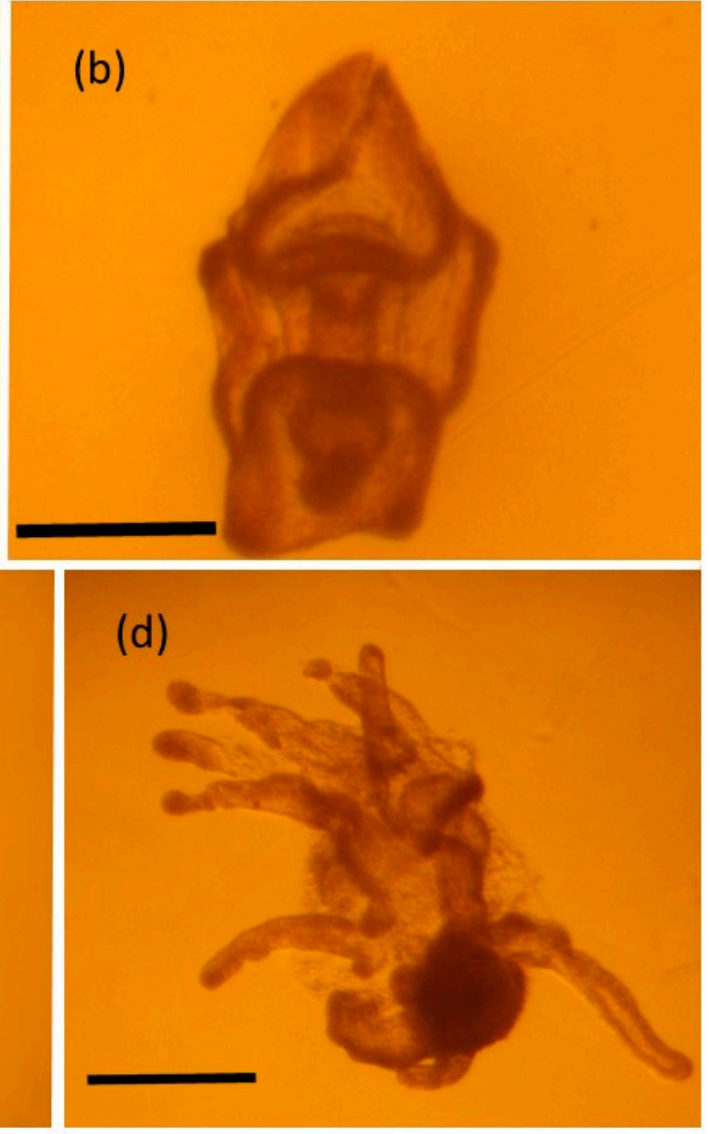

Figure 3. Field collected larvae with different developmental stages (a) gastrula, (b) bipinnaria and (c,d) brachiolaria larvae. Bars indicate $200 \mu \mathrm{m}$.

\subsection{Distribution of Nutrient and Chl-a Concentrations}

Mean seawater temperature and salinity at all sites were $29.6{ }^{\circ} \mathrm{C}$ and $34.0 \mathrm{psu}$ for the first and second surveys before the typhoon, which decreased to $28.8^{\circ} \mathrm{C}$ and $33.5 \mathrm{psu}$, respectively, after the typhoon (Figure S1a,b). The nutrients were distributed differently in the study area (Figure S1c-h). $\mathrm{NO}_{3}{ }^{-}$and $\mathrm{NO}_{2}{ }^{-}$concentrations (Figure S1c-h) in samples taken from calm water (prior to the typhoon) were low at all sites (mean \pm standard deviation [SD]: $0.136 \pm 0.164$ and $0.012 \pm 0.017 \mu \mathrm{M}$ for $\mathrm{NO}_{3}{ }^{-}$and $\mathrm{NO}_{2}{ }^{-}$, respectively), except for sites near the shoreline of Ishigaki and Iriomote Islands, and the northern reefs in Sekisei Lagoon, where concentrations were slightly higher (mean $\pm \mathrm{SD}$ : $0.220 \pm 0.144$ and $0.019 \pm 0.015 \mu \mathrm{M}$ for $\mathrm{NO}_{3}{ }^{-}$and $\mathrm{NO}_{2}{ }^{-}$, respectively). However, post-typhoon concentrations of both nutrients in Sekisei Lagoon were almost twice as high as the pre-typhoon concentrations (mean \pm SD: $0.303 \pm 0.214$ and $0.022 \pm 0.019 \mu \mathrm{m}$ for $\mathrm{NO}_{3}{ }^{-}$and $\mathrm{NO}_{2}{ }^{-}$, respectively). $\mathrm{PO}_{4}{ }^{3-}$ concentrations (Figure S2f) also increased at many sites from $0.04 \mu \mathrm{m}$ before the typhoon to $>0.06 \mu \mathrm{m}$ after the typhoon. Similarly, $\mathrm{SiO}_{2}$ concentrations increased within Sekisei Lagoon after rainfall brought by the typhoon. However, $\mathrm{NH}_{4}{ }^{+}$concentrations decreased from $0.37 \pm 0.80 \mu \mathrm{m}$ before the typhoon to $0.15 \pm 0.09 \mu \mathrm{m}$ after the typhoon. These nutrient distribution patterns were observed in samples taken at the surface and at a depth of $7 \mathrm{~m}$.

In contrast to the nutrients, the Chl- $a(>2 \mu \mathrm{m})$ concentration in calm, pre-typhoon surface water was relatively high $(0.35 \pm 0.30 \mu \mathrm{g} / \mathrm{L})$, particularly along the south side of Ishigaki Island, but decreased to $0.24 \pm 0.08 \mu \mathrm{g} / \mathrm{L}$ after the typhoon (Figure 4 ). However, mean Chl- $a$ concentration increased from $0.24 \pm 0.11$ to $0.29 \pm 0.10 \mu \mathrm{g} / \mathrm{L}$ after the typhoon at a depth of $7 \mathrm{~m}$. The Chl- $a$ starvation limit for A. planci larvae $(0.25 \mu \mathrm{g} / \mathrm{L}$; [7]) was exceeded at $\sim 43 \%$ of all sites during the first and second surveys at 
a depth of $7 \mathrm{~m}$ and at $\sim 57 \%$ of sites during the first survey at the surface. This limit was exceeded at $\sim 69 \%$ of sites at $7 \mathrm{~m}$ and $\sim 41 \%$ of the sites at the surface after the typhoon.

No spatial correlation was found between $A$. planci larval density and any of the nutrient or Chl- $a$ concentrations in our study area.

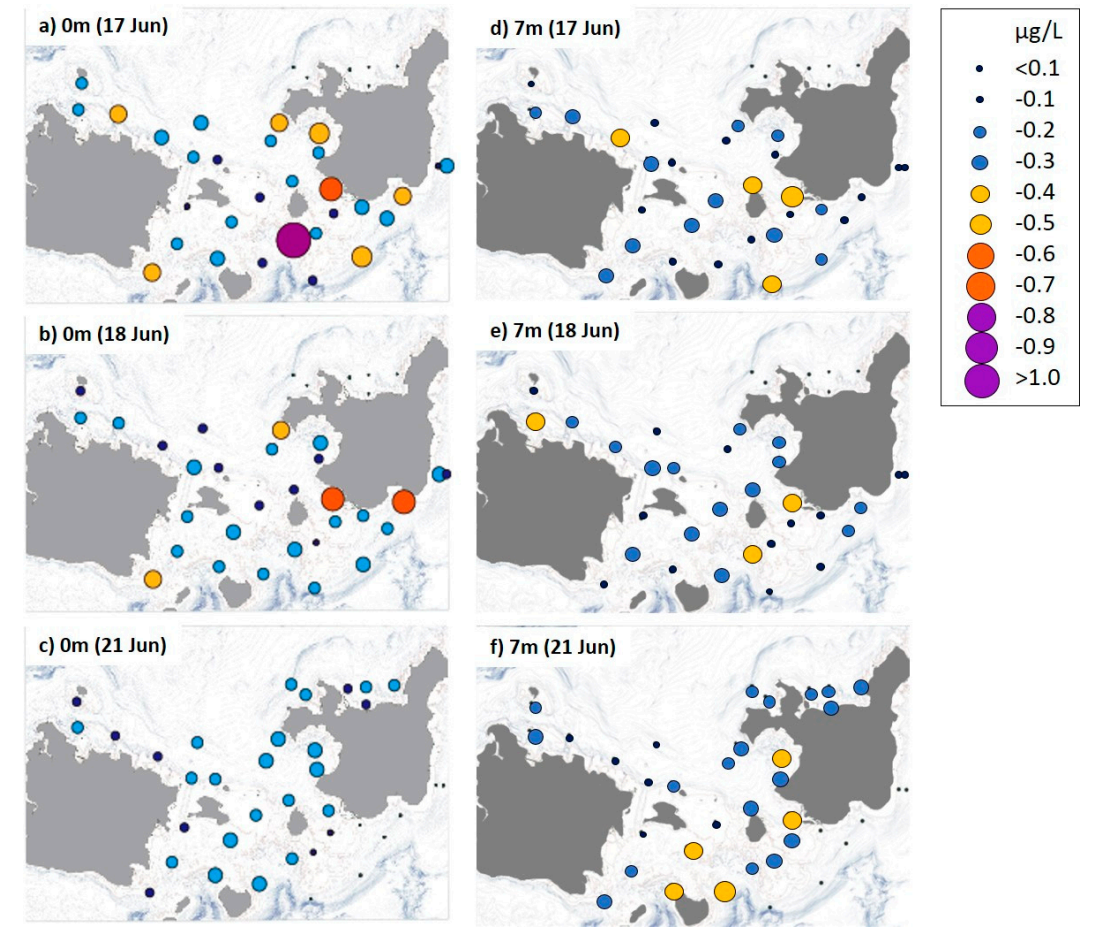

Figure 4. Distribution of chlorophyll (Chl)- $a$ concentrations in Sekisei Lagoon during three sampling days. $(\mathbf{a}-\mathbf{c})$ sampled at the surface $(0 \mathrm{~m})$ and $(\mathbf{d}-\mathbf{f})$ sampled $7 \mathrm{~m}$ below the surface.

\section{Discussion}

\subsection{High-Density A. Planci Larval Population before the Typhoon}

A high-density population of A. planci larvae occurred offshore near Yonara Channel, which connects the inner and outer waters of Sekisei Lagoon, before the typhoon (calm water). In addition, more than $90 \%$ of this population was in the late brachiolaria stage. Considering that it takes several days to develop to this stage, this result demonstrates that $A$. planci larvae were floating for some time and maintaining a high-density population, suggesting that relatively dense larval clouds could supply high-density recruitment to reefs, except during a large disturbance, such as a typhoon. Although we were unable to detect juveniles, local fishermen who eradicate A. planci around Sekisei Lagoon found a large number of $<1 \mathrm{~cm}$ juvenile $A$. planci around Yonara Channel during winter 2014, which may have settled in 2013. It would be worth testing the hypothesis that a high-density A. planci larval population can often be found around Yonara Channel in Sekisei Lagoon in a future study because Yonara Channel is an important spawning aggregation area for other species, such as white-streaked grouper [38]. In contrast, no relatively dense larval clouds were detected after the typhoon, and far fewer larvae were found. A typhoon increases terrestrial runoff, which would likely increase nutrient concentrations in the water column, but the inflow also mixes the water column, scattering any larvae and possibly preventing mass recruitment. Based on the limited observations in this study, it seems possible that the typhoon had negative effects on mass recruitment of $A$. planci larvae around Sekisei Lagoon. The typhoon flushed the stagnant nutrient-rich water discharged from the highly populated area south of Ishigaki Island, and an overall lower Chl- $a$ concentration was observed after the typhoon (Figure 3). Long-term monitoring of the A. planci population in some areas off the Okinawa mainland 
where chronic high density populations are observed [39] suggests that population outbreaks are less likely when a strong typhoon hits the reef [40]. Thus, the relative impact of terrestrial runoff associated with a typhoon (or cyclones) as an explanation for the increased survival rate of $A$. planci larvae near Okinawa may be smaller than reported by a previous study [14]. Our data indicate that the terrestrial runoff associated with typhoons may not increase COT larval survival, as previously hypothesized.

\subsection{A. Planci Larval Distribution and Density in Association with Food Availability}

We found no spatial correlation between the larval distribution and nutrients or Chl- $a$ concentrations that were hypothesized to be major indicators of larval food supply based on our limited three days of surveys. Besides, the quantity of phytoplankton available for $A$. planci larvae was low at sites where relatively dense larval clouds were found.

A. planci larvae begin to feed in the bipinnaria stage, but a large quantity of food is required for the rapid development observed in laboratory cultures. In the laboratory, larvae are fed unicellular algae, such as Dunaliella primolecta and Phaeodactylum tricornutum, to complete metamorphosis to the brachiolaria stage and then they eat less beginning in the late brachiolaria stage [41]. Although we have no information on the wild food sources of $A$. planci larvae, it is highly likely that food availability is more important during the bipinnaria stage than during the brachiolaria stage. Therefore, we cannot exclude the nutrient hypothesis, even though no spatial correlation was detected between the distribution of large-sized $(>2 \mu \mathrm{m})$ brachiolaria larvae and Chl- $a$ concentration in this study.

All of the sites in the entire Sekisei Lagoon area were food limiting for $A$. planci larvae, as modeled in a laboratory study [8] (i.e., Chl- $a$ concentrations did not exceed $2 \mu \mathrm{g} / \mathrm{L}$ ). Chl- $a$ concentrations exceeded the starvation level $(0.25 \mu \mathrm{g} / \mathrm{L}$ ) at only $40 \%$ of all sites (maximum $68 \%$ of all sites at a depth of 7-m after the typhoon), of which about $50 \%$ were near the south shore of highly populated Ishigaki Island, suggesting a relatively large anthropogenic effect on the increase of Chl- $a$ concentration in the study area. We did find dense clouds of advanced stage brachiolaria larvae, suggesting that $A$. planci bipinnaria and brachiolaria larvae had sufficient food to survive and developed at least until the late brachiolaria stage in this area.

Chl- $a$ concentrations were high in the calm, surface waters throughout Sekisei Lagoon but increased at a depth of $7 \mathrm{~m}$ after the typhoon. This increase was likely caused by water mixing during the typhoon, which moved phytoplankton concentrated near the surface to deeper water. Thus, A. planci larvae may have been transported to deeper water or far away from the reef where they could settle with their prey during the typhoon.

In addition to phytoplankton, relatively small quantities of dissolved organic matter (alanine and leucine) [42] and particular hormones, such as thyroxine, may contribute to A. planci larval growth [43]. Furthermore, the developmental rate of asteroidean larvae, including that of $A$. planci, is largely dependent on the quantity and quality of their phytoplankton prey $[8,15,44]$. Developing larvae are exposed to a particular daily mortality risk. Consequently, if the planktonic period between hatching and settlement to metamorphose into the adult stage is shortened by even a few days, considerably larger numbers of larvae are likely to be recruited into later life stages $[17,18]$ than if the larvae continue to swim longer until they find a suitable place to settle.

Our results do not dismiss the nutrient hypothesis, but a recent study reported population outbreaks of $A$. planci on an isolated and unpopulated reef atoll in the absence of high nutrient concentrations [45], suggesting that nutrients are not always the cause of an A. planci population outbreak.

\subsection{Possible A. Planci Larval Dispersal inside and outside Sekisei Lagoon}

Many adult $A$. planci were found in the northern reefs of Sekisei Lagoon, where coral cover is high. The high acroporid coral cover around Yonara Channel and the northern reefs of Sekisei Lagoon [25] may support large $A$. planci adult populations and allow them to produce a larger number of gametes than low coral cover areas encountered elsewhere in the study area. However, similar to the long-range 
larval transportation expected in the Great Barrier Reef [20,46] and the genetic homogeneity found in the region [47-49], it is also possible that large numbers of larvae were transported from remote regions to areas near Yonara Channel through long-range larval dispersal. No significant population gene flow differences have been reported in the Kuroshio region (from the Philippines to south of the Japanese mainland), including Sekisei Lagoon, based on seven highly polymorphic microsatellite loci [49]. Therefore, the source of the larvae, particularly the late brachiolaria stage larvae found in this study, may not necessarily be Sekisei Lagoon.

\subsection{Screening Method Used in This Study}

PCR amplification of the crude samples failed to detect $A$. planci larvae in seawater. Sequences from other organisms and/or any parts of $A$. planci adults called "environmental DNA," which are similar to $A$. planci target sequences, may have been amplified, thus yielding the observed false positive results for the presence of $A$. planci larvae in the crude samples. The failure of the PCR method may also be associated with several inhibitors, low concentrations of target DNA in the crude samples, and/or low species specificity of the primers. More sophisticated primers have become available [20], but DNA degradation prevented us from reanalyzing our samples. It is expected that a method to quantitatively detect $A$. planci larvae in the crude samples will be established in the future.

\subsection{Future Perspectives; Prediction of Population Outbreaks}

It is necessary to understand the dynamics of larval populations to predict or prevent $A$. planci outbreaks. Although primary outbreaks can be predicted based on the significant relationship between sea star populations and the North Pacific Transition Zone Chlorophyll Front in the North central Pacific Islands [50], predicting secondary outbreaks remains difficult. Our results show high densities of $A$. planci brachiolaria larvae within the outer reef channels over at least two days. These relatively high-density larval clouds, which are expected to be recruited en masse to the adult stage, are a potential trigger for the next outbreak (i.e., a recruitment hotspot). Such mass settlements of $A$. planci larvae are more likely to occur in deep coral rubble than in shallow water [51,52]. Post-settlement mortality of one-month-old larvae has been estimated to be $6.49 \%$ of the population per day, resulting mainly from predation by epibenthic animals, such as shrimp and polychaetes [11,17]. However, simultaneous extremely high density mass recruitment could overcome such predation pressure. The enhanced growth of juvenile A. planci experimentally fed Acropora and Pocillopora, compared with those fed Porites and Turbinaria [11], suggests that $A$. planci larval aggregations in our study area may be associated with the availability of high acroporid coral cover, which may also increase the survival rate of juvenile $A$. planci. Therefore, sites with high acroporid coral cover near reef channels should be investigated as an origin for potential adult outbreaks. More research on the potential of A. planci to swim vertically and selective settlement of $A$. planci larvae, as well as improvements in the methods to estimate larval density, are important for improving our understanding of the mechanisms that underpin A. planci outbreaks and consequently destroy coral reefs.

Supplementary Materials: The following are available online at www.mdpi.com/1424-2818/8/2/9/s1, Figure S1: Distributions of temperature (a); salinity (b); nutrient concentrations (c-g); $\mathrm{NH}_{4}{ }^{+}, \mathrm{NO}_{2}{ }^{-}, \mathrm{NO}_{3}{ }^{-}, \mathrm{PO}_{4}{ }^{3-}$, and $\mathrm{SiO}_{2}$ ); (h) dissolved oxygen (DO); and (i) turbidity at the surface and at a depth of $7 \mathrm{~m}$ in Sekisei Lagoon during 3 days of sampling, Table S1: Number of larvae isolated under a microscope $(n=225)$ and larvae identified using polymerase chain reaction (PCR) and sequencing analyses ( $n=42$ in total), Table S2: The most closely related species obtained from larval DNA other than Acanthaster planci based on a BLAST search using the partial cytochrome oxidase subunit 1 (CO1) sequence. GS: gastrula, BP: bipinnaria, BR, brachiolaria. These stages were identified using echinoderm universal CO1 primers following the protocol of Arndt et al. (1996) [1].

Acknowledgments: This research was supported by the Environment Research and Technology Development Fund (4-1304) of the Ministry of the Environment, Japan. We thank active ranger H. Haruguchi for assistance with the field surveys, and we also thank Masatoshi Morita for advice on data analyses. We thank Yuko F. Kitano, Yuta Saito, Aki Nakabayashi for their assistance in field and laboratory work.

Author Contributions: N.Y., K.F., G.S., A.W., and K.N. conceived and designed the experiments; N.Y., K.I., K.F., T.K., S.K., G.S., S.N., A.W., Ti.N., S.K., and L.P.C.B. performed the experiments; N.Y., K.I., K.F., A.W., M. K. and 
Tt.N. analyzed the data; N.Y., K.I., M.K., Ti.N., and K.F. contributed reagents, materials, and analytical tools; G.S., N.Y., K.F., and A.W. wrote the manuscript.

Conflicts of Interest: The authors declare no conflicts of interest.

\section{References}

1. Pratchett, M.S.; Caballes, C.F.; Rivera-Posada, J.A.; Sweatman, H.P.A. Limits to understanding and managing outbreaks of crown-of-thorns starfish (Acanthaster spp.). In Oceanography and Marine Biology: An Annual Review; Hughes, R.N., Hughes, D.J., Smith, I.P., Eds.; CRC Press: Boca Raton, FL, USA, 2014; Volume 52, pp. 133-200.

2. Pratchett, M. Dynamics of an outbreak population of Acanthaster planci at Lizard Island, northern Great Barrier Reef (1995-1999). Coral Reefs 2005, 24, 453-462. [CrossRef]

3. Endean, R. Acanthaster planci infestations on reefs of the Great Barrier Reef. In Proceedings of the Third International Coral Reef Symposium, Miami, FL, USA, May 1977; Volume 1, pp. 185-191. Available online: http:/ / www.reefbase.org/resource_center/publication/icrs.aspx?icrs=ICRS3 (accessed on 31 March 2016).

4. Moran, P.; De'ath, G.; Baker, V.; Bass, D.; Christie, C.; Miller, I.; Miller-Smith, B.; Thompson, A. Pattern of outbreaks of crown-of-thorns starfish (Acanthaster planci L.) along the Great Barrier Reef since 1966. Mar. Freshw. Res. 1992, 43, 555-567. [CrossRef]

5. Yamaguchi, M. Acanthaster planci infestations of reefs and coral assemblages in Japan: A retrospective analysis of control efforts. Coral Reefs 1986, 5, 23-30. [CrossRef]

6. Suzuki, G.; Kai, S.; Yamashita, H. Mass stranding of crown-of-thorns starfish. Coral Reefs 2012, $31,821$. [CrossRef]

7. Yasuda, N. Implications from the records of population outbreaks of crown-of-thorns Starfish Acanthaster planci in Japan over 100 years (1912-2015). In Coral Reef Studies in Japan; Iguchi, A., Hongo, C., Eds.; Chapter 10; Springer: Tokyo, Japan, 2016; under review.

8. Fabricius, K.E.; Okaji, K.; De'ath, G. Three lines of evidence to link outbreaks of the crown-of-thorns seastar Acanthaster planci to the release of larval food limitation. Coral Reefs 2010, 29, 593-605. [CrossRef]

9. Birkeland, C.; Lucas, J.S. Acanthaster Planci: Major Management Problem of Coral Reefs; CRC Press: Boca Raton, FL, USA, 1990.

10. Yamaguchi, M. Larval behavior and geographic distribution of coral reef asteroids in the Indo-West Pacific. Micronesia 1977, 13, 283-296.

11. Keesing, J.; Halford, A. Importance of postsettlement processes for the population dynamics of Acanthaster planci (L.). Mar. Freshw. Res. 1992, 43, 635-651. [CrossRef]

12. Birkeland, C. Terrestrial runoff as a cause of outbreaks of Acanthaster planci (Echinodermata: Asteroidea). Mar. Biol. 1982, 69, 175-185. [CrossRef]

13. Brodie, J. Enhancement of larval and juvenile survival and recruitment in Acanthatser planci from the effects of terrestrial runoff: A review. Mar. Freshw. Res. 1992, 43, 539-553. [CrossRef]

14. Brodie, J.; Fabricius, K.; De'ath, G.; Okaji, K. Are increased nutrient inputs responsible for more outbreaks of crown-of-thorns starfish? An appraisal of the evidence. Mar. Pollut. Bull. 2005, 51, 266-278. [CrossRef] [PubMed]

15. Wolfe, K.; Graba-Landry, A.; Dworjanyn, S.A.; Byrne, M. Larval starvation to satiation: Influence of nutrient regime on the success of Acanthaster planci. PLoS ONE 2015, 10, e0122010. [CrossRef] [PubMed]

16. Wolfe, K.; Graba-Landry, A.; Dworjanyn, S.A.; Byrne, M. Larval phenotypic plasticity in the boom-and-bust crown-of-thorns seastar, Acanthaster planci. Mar. Ecol. Prog. Ser. 2015, 539, 179-189. [CrossRef]

17. Keesing, J.; Halford, A. Field measurements of survival rates of juvenile Acanthaster planci: Techniques and preliminary results. Mar. Ecol. Prog. Ser. 1992, 85, 107-114. [CrossRef]

18. Sweatman, H. No-take reserves protect coral reefs from predatory starfish. Curr. Biol. 2008, 18, R598-R599. [CrossRef] [PubMed]

19. Yasuda, N.; Kajiwara, K.; Nagai, S.; Ikehara, K.; Nadaoka, K. The first report of field sampling and identification of the crown-of-thorns starfish larvae. Galaxea 2015, 17, 1-2. [CrossRef]

20. Uthicke, S.; Doyle, J.; Duggan, S.; Yasuda, N.; McKinnon, A.D. Outbreak of coral-eating Crown-of-Thorns creates continuous cloud of larvae over $320 \mathrm{~km}$ of the Great Barrier Reef. Sci. Rep. 2015, 5, 16885. [CrossRef] [PubMed] 
21. Lu, L.F.; Miyazawa, Y.; Cui, W.; Nadaoka, K. Numerical study of surface water circulation around Sekisei Lagoon, southwest Japan. Ocean Dyn. 2010, 60, 359-375. [CrossRef]

22. Nadaoka, K.; Mitsui, J.; Hamasaki, K.; Harii, S.; Tamura, J.; Suzuki, Y. Field measurements of currents and turbidity, freshwater and thermal transport characteristics in Sekisei lagoon, Okinawa. Proc. Coast. Eng. JSCE 2003, 50, 1036-1040. (In Japanese)

23. Hasegawa, H.; Yamano, H. Status of coral reefs around the country. In Coral Reefs of Japan; Ministry of the Environment, Japanese Coral Reef Society: Tokyo, Japan, 2004; pp. 153-286.

24. Yasuda, N.; Ogasawara, K.; Kajiwara, K.; Ueno, M.; Oki, K.; Taniguchi, H.; Kakuma, S.; Okaji, K.; Nadaoka, K. Latitudinal differentiation of crown-of-thorns starfish (Acanthaster planci) in the reproduction patterns through the Ryukyu Island archipelago. Plankton Benthos Res. 2010, 5, 156-164. [CrossRef]

25. Ministry of the Environment BCiJ. Annual Report of Coral Reef Monitoring around Sekisei Lagoon National Park and Its Surrounding Areas (H26, May 2014), Available online: http://www.biodic.go.jp/ moni1000/findings/reports/index.html (accessed on 31 March 2016).

26. Motoda, S. North Pacific standard plankton net. Inf. Bull. Planktology Japan 1957, 4, 13-15.

27. Vogler, C.; Benzie, J.A.H.; Tenggardjaja, K.; Ambariyanto-Barber, P.H.; Wörheide, G. Phylogeography of the crown-of-thorns starfish: Genetic structure within the Pacific species. Coral Reefs 2013, 32, 515-525. [CrossRef]

28. Timmers, M.; Bird, C.; Skillings, D.; Smouse, P.; Toonen, R. There's no place like home: Crown-of-thorns outbreaks in the Central Pacific are regionally derived and independent events. PLoS ONE 2012, 7, e31159. [CrossRef] [PubMed]

29. Timmers, M.A.; Andrews, K.R.; Bird, C.E.; de Maintenton, M.J.; Brainard, R.E.; Toonen, R.J. Widespread dispersal of the crown-of-thorns sea star, Acanthaster planci, across the Hawaiian archipelago and Johnston atoll. J. Mar. Biol. 2011, 2011, 10. [CrossRef]

30. Yasuda, N.; Taquet, C.; Nagai, S.; Yoshida, T.; Adjeroud, M. Genetic connectivity of the coral-eating sea star Acanthaster planci during the severe outbreak of 2006-2009 in the Society Islands, French Polynesia. Mar. Ecol. 2015, 36, 668-678. [CrossRef]

31. Hall, T.A. BioEdit: A user-friendly biological sequence alignment editor and analysis program for Windows 95/98/NT. In Nucleic Acids Symposium Series; Oxford University Press: Oxford, UK, 1999; Volume 41, pp. 95-98.

32. Meeker, N.D.; Hutchinson, S.A.; Ho, L.; Trede, N.S. Method for isolation of PCR-ready genomic DNA from zebrafish tissues. Biotechniques 2007, 43, 610, 612 and 614. [CrossRef] [PubMed]

33. The General Environmental Techinos co., LTD. Available online: http://www.kanso.co.jp/eng/index.html (accessed on 10 May 2016).

34. Suzuki, R.; Ishimaru, T. An improved method for the determination of phytoplankton chlorophyll using N, N-dimethylformamide. J. Oceanogr. Soc. Japan 1990, 46, 190-194. [CrossRef]

35. Holm-Hansen, O.; Lorenzen, C.J.; Holmes, R.W.; Strickland, J.D.H. Fluorometric determination of chlorophyll. J. Cons. 1965, 30, 3-15. [CrossRef]

36. Moran, P.A.P. Notes on continuous stochastic phenomena. Biometrika 1950, 37, 17-23. [CrossRef] [PubMed]

37. Anselin, L. Local indicators of spatial association-LISA. Geogr. Anal. 1995, 27, 93-115. [CrossRef]

38. Nanami, A.; Ohta, I.; Sato, T. Estimation of spawning migration distance of the white-streaked grouper (Epinephelus ongus) in an Okinawan coral reef system using conventional tag-and-release. Environ. Biol. Fishes 2014, 98, 1387-1397. [CrossRef]

39. Nakamura, M.; Okaji, K.; Higa, Y.; Yamakawa, E.; Mitarai, S. Spatial and temporal population dynamics of the crown-of-thorns starfish, Acanthaster planci, over a 24-year period along the central west coast of Okinawa Island, Japan. Mar. Biol. 2014, 161, 2521-2530. [CrossRef]

40. Yamaguchi, M.; (Luminous Himuka Research Institute, Miyazaki, Japan). personal communication, 18 August 2012.

41. Lucas, J.S. Quantitative studies of feeding and nutrition during larval development of the coral reef asteroid Acanthaster planci (L.). J. Exp. Mar. Biol. Ecol. 1982, 65, 173-193. [CrossRef]

42. Hoegh-Guldberg, O. Uptake of dissolved organic matter by larval stage of the crown-of-thorns starfish Acanthaster planci. Mar. Biol. 1994, 120, 55-63.

43. Johnson, L.G.; Cartwright, C.M. Thyroxine-accelerated larval development in the crown-of-thorns starfish, Acanthaster planci. Biol. Bull. 1996, 190, 299-301. [CrossRef] 
44. Basch, L.V. Effects of algal and larval densities on development and survival of asteroid larvae. Mar. Biol. 1996, 126, 693-701. [CrossRef]

45. Roche, R.C.; Pratchett, M.S.; Carr, P.; Turner, J.R.; Wagner, D.; Head, C.; Sheppard, C.R. Localized outbreaks of Acanthaster planci at an isolated and unpopulated reef atoll in the Chagos Archipelago. Mar. Biol. 2015, 162, 1695-1704. [CrossRef]

46. Dight, I.; James, M.; Bode, L. Modelling the larval dispersal of Acanthaster planci II. Patterns of reef connectivity. Coral Reefs 1990, 9, 125-134. [CrossRef]

47. Nash, W.J.; Goddard, M.; Lucas, J.S. Population genetic studies of the crown-of-thorns starfish, Acanthaster planci (L.), in the Great Barrier Reef region. Coral Reefs 1988, 7, 11-18. [CrossRef]

48. Benzie, J. Review of the genetics, dispersal and recruitment of crown-of-thorns starfish (Acanthaster planci). Mar. Freshw. Res. 1992, 43, 597-610. [CrossRef]

49. Yasuda, N.; Nagai, S.; Hamaguchi, M.; Okaji, K.; Gérard, K.; Nadaoka, K. Gene flow of Acanthaster planci (L.) in relation to ocean currents revealed by microsatellite analysis. Mol. Ecol. 2009, 18, 1574-1590. [CrossRef] [PubMed]

50. Houk, P.; Bograd, S.; van Woesik, R. The transition zone chlorophyll front can trigger Acanthaster planci outbreaks in the Pacific Ocean: Historical confirmation. J. Oceanogr. 2007, 63, 149-154. [CrossRef]

51. Johnson, C. Settlement and recruitment of Acanthatser planci on the Great Barrier Reef: Questions of process and scale. Mar. Freshw. Res. 1992, 43, 611-627. [CrossRef]

52. Johnson, C.; Sutton, D.; Olson, R.; Giddins, R. Settlement of crown-of-thorns starfish: Role of bacteria on surfaces of coralline algae and a hypothesis for deepwater recruitment. Mar. Ecol. Prog. Ser. 1991, 71, 143-162. [CrossRef]

(C) 2016 by the authors; licensee MDPI, Basel, Switzerland. This article is an open access article distributed under the terms and conditions of the Creative Commons by Attribution (CC-BY) license (http://creativecommons.org/licenses/by/4.0/). 